\title{
ASPECTOS RELEVANTES DAS RESPONSABILIDADES NAS RELAÇÕES CONSUMERISTAS ELETRÔNICAS
}

\author{
RELEVANT ASPECTS OF RESPONSIBILITIES IN ELECTRONIC CONSUMERISTAS RELATIONS
}

Florence Cronemberger Haret Drago

Doutora em direito tributário pela Faculdade de Direito do Largo São Francisco, Universidade de São Paulo; endereço eletrônico: florence @institutoidea.net.br

Recebido em: 15.08 .2014

Aprovado em: 19.02.2016

DOI: $10.5585 /$ rdb.v12i5.252

\section{Resumo}

Em um mundo cada vez mais globalizado, a responsabilidade nas relações de consumo, ocorridas no ambiente do comércio eletrônico, é o tema do momento e deve ser repensado de acordo com uma hermenêutica jurídica mais clara e objetiva. E estetópico pede algumas reflexões mais aprofundadas sobre os tipos de agentes presentes nessa relação consumeristas eletrônicas, aplicando, com adaptações próprias do contexto, as regras do CDC ao fato ou vício do produto nas relações de comércio eletrônico, fazendo as distinções necessárias sobre os diferentes provedores, verificando as diferenças existentes entre site-fornecedor, sitecomerciante e site de intermediação e seus reflexos no âmbito das responsabilidades, identificando os limites da responsabilidade das redes sociais e, por fim, de seus usuários em face do provedor de conteúdo. O presente texto, nesse sentido, busca dar um panorama global das responsabilidades nas relações consumeristas eletrônicas, demonstrando seus aspectos relevantes e como a jurisprudência tem julgado o tema.

Palavras-chave: comércio eletrônico, responsabilidade civil, provedor, rede social, usuário

\begin{abstract}
In an increasingly globalized world, the responsibility in consumer relations, occurred in the e-commerce environment, is the theme of the moment and should be redesigned in accordance with a clear and objective legal interpretation. And this topic asks some further discussion about the types of agents that electronic consumerist's relation applying the rules of the CDC to the fact or defect of the product in e-commerce relationships with respecting it'sown adjustments, making the necessary distinctions about the different providers, checking the differences between supplier's site, commerciant's site and intermediation's site and its effects within theirs responsibilities, identifying the limits of liability of social networks and, finally, of its members in the face of the content provider. This text, in this sense, seeks to
\end{abstract}


give an overview of the responsibilities in electronic consumeristas relations, demonstrating material respects and the case law has held the theme.

Key-words: e-commerce, civil liability, provider, social network, user.

\section{Introdução}

Cada vez mais, o comércio vem se utilizando do ambiente da internet para otimizar suas atividades, acrescendo em termos exponenciais o número de relações de consumo entre fornecedores e consumidores. De fato, a internet potencializa coleta de dados, oferta, publicidade e contratação, tornando ainda mais massificada, do que já seja, a atividade de fornecimento de produto ou de serviço. É um excelente instrumento de comunicação e de oferecimento de bens e de prestações de serviços que todos os fornecedores têm acesso. Esse aumento de quantidade e de velocidade em que as relações se estabelecem no campo da internet traz, como contrapartida, uma constante necessidade de controle e criação de novas responsabilidades pela lei, uma vez que ilicitudes acometidas na internet atingem um número muito maior de pessoas, propiciando prejuízos incalculáveis para a sociedade.

Sob o ponto de vista do consumidor, se de um lado o espaço cibernético aumenta a sua vulnerabilidade perante o fornecedor, por outro, propicia seu fortalecimento ao serem criados mecanismos de controle de qualidade pelos próprios usuários, numa espécie de "novo SAC" ou "Auto-SAC". De fato, reclamações de consumidores na internet, proporcionais e embasadas, são extremamente benéficas ao mercado, na medida em que contribuem na autoregulação das práticas do mercado. Contudo, mal utilizadas, propiciando abusos, ensejam responsabilidades e são prejudiciais não somente aos consumidores, como também, e nesse caso principalmente, aos próprios fornecedores ou seus concorrentes. Daí a necessidade de se obter mecanismos que inviabilizem condutas ilícitas sem prejudicar a liberdade de expressão ou de manifestação.

Acresce-se a isso tudo o fato de que a internet é uma estrutura complexa, em que em uma só relação vários agentes são participantes, exercendo diferentes funções, todos eles partes de um processo só em que a ausência de qualquer das fases inviabiliza o todo. Considerando ainda que esses mesmos sujeitos operam muitas vezes com mecanismos que geram dúvida sobre a autoria de determinada mensagem, propiciando o anonimato e as 
irresponsabilidades. Todos esses pontos são fundamentais para se repensar sobre os aspectos relevantes das responsabilidades nas relações consumeristas eletrônicas e verificar até que ponto os enunciados do Código de Defesa do Consumidor deverão ser reinterpretados segundo as imposições das próprias características advindas das relações na internet. Não se busca com isso a fragmatização dos conceitos, utilizando a expressão germânica utilizada pela profa. Cláudia Lima Marques, ${ }^{1}$ mas de uma hermenêutica de integração entre o direito e a realidade, entre os conceitos isoladas e uma análise contextual.

Cabe apontar que o tema é de extrema atualidade e tem sido objeto de muitas pesquisas. Vários centros de estudos do e-commerce têm sido criados para atender, em termos regulatórios, as novas práticas e relações consumeristas no ambiente da internet, tais como as constantes Notas Técnicas do SENACON (Secretaria Nacional do Consumidor) e os estudos produzidos pela escola nacional de defesa do consumidor.

O executivo, por sua vez, também tem sido demandado no sentido de produzir Legislação mais específica sobre a matéria. E isso tem sido feito, com normas de diferentes níveis regulatórios. Citemos, exemplificando, o Decreto Presidencial 7.962/13, que regula o sobre a contratação no comércio eletrônico; ou a Nota Técnica SENACON 40, de 11/09/12, explicativa da relação no comércio eletrônico, especialmente sobre informações na oferta, contratação e direito de arrependimento.

Mais recentemente, a Lei $n^{\circ}$ 12.965, de 23 de abril de 2014 (Projeto de lei 2.126), conhecida como o Marco civil da internet, trouxe expressivos reflexos na regulação dos direitos do consumidor e nas responsabilidades de fornecedores e consumidores no uso da internet.Foram incluídos parâmetros para melhorar o acesso à rede, tais como regras de responsabilidade entre provedores e usuários, preservação da privacidade, liberdade de expressão e a garantia para o bom funcionamento e operacionalidade. Não tratou de questões importantes, contudo, deixando de lado temas como direitos autorais, certificação digital, spam, cibercrimes e demais irregularidades recorrentes neste ambiente. Significou um grande avanço sobre o tema das responsabilidades no ambiente da internet e, ainda que não tenha regulado expressamente alguns pontos, trouxe preceitos mais abertos, usados já como parâmetro para fins de controlar as atividades cibernéticas.

Cabe apontar ainda que, em sendo o direito uno e indecomponível, outros preceitos devem ser lidos juntos com a Lei $\mathrm{n}^{\mathrm{o}} 12.965 / 14$, tais como a Lei de direitos autorais (Lei 
$\mathrm{n}^{\circ}$ 9.610/98) contextualizada ao ambiente da internet, a Lei dos crimes cibernéticos ou Lei Carolina Dieckmann/Azeredo (Lei no 12.737/12).

Para Cláudia Lima Marques, "a maioria da doutrina brasileira concorda que é necessária uma melhor e mais específica regulamentação legislativa do comércio eletrônico".2 Por outro lado, Ricardo Barreto ensina que "ao contrato celebrado no comércio eletrônico aplicam-se as normas jurídicas civis e consumeristas já existentes, não precisando disciplinálo em lei própria." ${ }^{3}$ Vê-se pois que nem todos entendem salutar a regulamentação dessa área, uma vez que a lei engessaria as possibilidades comerciais e de responsabilidades. Certo é que a Lei $n^{\circ} 12.965 / 14$ trouxe alguns impactos negativos aos consumidores. Exemplificando: ao proibir empresas de oferecerem planos diferenciados de acordo com a necessidade personalizada do consumidor, tornou seus serviços mais restritos e menos atraentes.

Diante de todo esse novo contexto regulatório, da complexidade das relações cibernéticas e da potencialidade lesiva que os abusos acometidos nesse ambiente propiciam, cabe trazer neste artigo algumas considerações sobre as diferentes responsabilidades que estão em jogo no campo da internet. A ideia é identificar as razões e os critérios para se dizer que tal ou qual agente deve ser responsabilizado, identificando os fundamentos legais e principiológicos utilizados.

\section{Marco civil da internet: princípios regentes}

$\mathrm{Na}$ linha de identificar as responsabilidades existentes no espaço cibernético, cumpre, primeiramente, conhecer os princípios regentes da matéria, afinal está na própria palavra a mensagem de que toda interpretação deverá iniciar-se pelo seu "princípio", pela sua ideia inicial. Os princípios são, portanto, o ponto de partida de toda exegese de modo que as responsabilidades imputadas devem estar em consonância com os ditames maiores que regulam a matéria.

O marco civil da internet, em seu artigo $3^{\circ}$ trouxe seus principais princípios regentes, quais sejam:

I - garantia da liberdade de expressão, comunicação e manifestação de pensamento, nos termos da Constituição Federal;

II - proteção da privacidade; 
III - proteção dos dados pessoais, na forma da lei;

IV - preservação e garantia da neutralidade de rede;

V - preservação da estabilidade, segurança e funcionalidade da rede, por meio de medidas técnicas compatíveis com os padrões internacionais e pelo estímulo ao uso de boas práticas;

VI - responsabilização dos agentes de acordo com suas atividades, nos termos da lei;

VII - preservação da natureza participativa da rede;

VIII - liberdade dos modelos de negócios promovidos na internet, desde que não conflitem com os demais princípios estabelecidos nesta Lei.

Tal lista não possui rol taxativo de modo que não nega aplicabilidade à matéria de outros previstos no ordenamento jurídico pátrio ou mesmo tratados internacionais em que a República Federativa do Brasil seja parte, como bem adverte o artigo $3^{\circ}$, em seu parágrafo único.

No campo dos direitos e garantias do usuário, disposto no artigo $7^{\circ}$ da Lei $n^{\circ}$ 12.965/14, o dispositivo legal traz outros princípios, tais como:

I - inviolabilidade da intimidade e da vida privada, sua proteção e indenização pelo dano material ou moral decorrente de sua violação;

II - inviolabilidade e sigilo do fluxo de suas comunicações pela internet, salvo por ordem judicial, na forma da lei;

III - inviolabilidade e sigilo de suas comunicações privadas armazenadas, salvo por ordem judicial;

IV - não suspensão da conexão à internet, salvo por débito diretamente decorrente de sua utilização;

V - manutenção da qualidade contratada da conexão à internet;

VI - informações claras e completas constantes dos contratos de prestação de serviços, com detalhamento sobre o regime de proteção aos registros de conexão e aos registros de acesso a aplicações de internet, bem como sobre práticas de gerenciamento da rede que possam afetar sua qualidade;

VII - não fornecimento a terceiros de seus dados pessoais, inclusive registros de conexão, e de acesso a aplicações de internet, salvo mediante consentimento livre, expresso e informado ou nas hipóteses previstas em lei;

VIII - informações claras e completas sobre coleta, uso, armazenamento, tratamento e proteção de seus dados pessoais, que somente poderão ser utilizados para finalidades que: a) justifiquem sua 
coleta; b) não sejam vedadas pela legislação; e c) estejam especificadas nos contratos de prestação de serviços ou em termos de uso de aplicações de internet;

IX - consentimento expresso sobre coleta, uso, armazenamento e tratamento de dados pessoais, que deverá ocorrer de forma destacada das demais cláusulas contratuais;

$\mathrm{X}$ - exclusão definitiva dos dados pessoais que tiver fornecido a determinada aplicação de internet, a seu requerimento, ao término da relação entre as partes, ressalvadas as hipóteses de guarda obrigatória de registros previstas nesta Lei;

XI - publicidade e clareza de eventuais políticas de uso dos provedores de conexão à internet e de aplicações de internet;

XII - acessibilidade, consideradas as características físico-motoras, perceptivas, sensoriais, intelectuais e mentais do usuário, nos termos da lei; e

XIII - aplicação das normas de proteção e defesa do consumidor nas relações de consumo realizadas na internet.

Na seção "da neutralidade da rede", a referida Lei identifica deveres imputados ao responsável pela transmissão, comutação ou roteamento, considerado aqui tal qual um fornecedor. Nesses deveres, estão por detrás fortes mensagens não só de responsabilidade mas de princípio, contribuindo também para conformar esse ponto de partida interpretativo que se busca identificar nesse item. Cite-se:

I - abster-se de causar dano aos usuários;

II - agir com proporcionalidade, transparência e isonomia;

III - informar previamente de modo transparente, claro e suficientemente descritivo aos seus usuários sobre as práticas de gerenciamento e mitigação de tráfego adotadas, inclusive as relacionadas à segurança da rede; e

IV - oferecer serviços em condições comerciais não discriminatórias e abster-se de praticar condutas anticoncorrenciais.

Diante dessa multiplicidade de princípios regulatórios, há que se ter em mente que todos eles devem ser ponderados no caso em concreto. Assim, nega-se qualquer cunho meramente programático a esses enunciados, dando-lhes eficácia positiva (criando obrigações) e negativa (impondo abstenções) para conformar as hipóteses de responsabilidades no ambiente da internet. Busca-se, portanto, toma-los como cláusulas gerais ou conceitos determinados pelas imposições do problema, sendo, por si sós, normas 
impositivas de condutas e de sanções. O que se busca é,portanto, a defesa da liberdade de expressãode comunicação e dos modelos de negócios promovidos na internet; da privacidade, ${ }^{4}$ inviolabilidade e sigilo, protegendo dados pessoais, na forma da lei; do tratamento igualitário, preservando e garantindo a neutralidade de rede; da transparência e informação nas relações cibernéticas; da responsabilização dos agentes de acordo com suas atividades; da preservação da estabilidade, segurança e funcionalidade da rede, dentre todos os demais que se possa trazer do ordenamento e aplicar à matéria analogicamente. Esse, portanto, será o ponto de partida para se conjectura das responsabilidades no comércio eletrônico.

\section{Comércio eletrônico}

Em face dos princípios acima enumerados e do superior potencial lesivo já demonstrado nos itens anteriores, cumpre afirmar que o relacionamento virtual exige um grau muito maior de confiança e de segurança. E não poderia ser diferente pois, muitas vezes, o consumidor sequer sabe com quem está contratando.

Por isso mesmo é que, para que o comércio eletrônico seja viável, é necessário o respeitoaos seguintesaspectosinafastáveis em quaisquer de seus formatos:

1. Conferir informações claras a respeito do produto, serviço e do fornecedor;

2. Atendimento facilitado ao consumidor; e

3. Respeito ao direito de arrependimento.

Partindo-se do pressuposto de que, no comércio eletrônico, há claramente um agravamento da vulnerabilidade do consumidor, as regras de responsabilidades dos fornecedores ganharam maior abrangência e real eficácia. Evidentemente que nessa assertiva não se afirma a imposição de responsabilidades para quem não tenha poder de gestão sobre as informações veiculadas ou qualquer ganho na relação comercial formada. Não se deve interpretar o comércio eletrônico de modo a inviabilizá-lo, responsabilizando aquele que possui ligação indireta ou ínfima com a situação ilícita. Não se pode, também, propiciar enriquecimentos sem causa ou ilícitos, ensejando sistemas de responsabilidades que deixe de punir os verdadeiros autores dos abusos. Contudo, deve-se evitar práticas ilícitas 
potencializadas no ambiente da internet como o assédio de consumo produzindo o boxing. Esta expressão, segundo Saddi, consiste "na prática de pressão ao consumidor para a aquisição de algum produto mediante o estímulo por meio de ofertas 'demasiadamente' vantajosas," "apresentando o produto ou serviço de uma maneira limitada e direcionada.

Na locução "comércio eletrônico" estão inseridos diversos tipos ou formatos de estabelecimentos virtuais. Há o "E-commerce puro", onde comparecem fornecedores sem estabelecimento físico, transacionando apenas pela internet (Ex. Submarino, Amazon, ...); o "E-commerce misto", atuando por meio de Lojas físicas e lojas virtuais; ou ainda o "Social commerce", ou seja, o comércio produzido pela via das próprias redes sociais. Nada mais são do que lojas virtuais estabelecidas dentro de sites de redes sociais.

Em todos esses casos, a lei impõe certas informações obrigatórias no site para fins de diminuir as instabilidades de relações não-presenciais, com estabelecimentos físicos muitas vezes inexistentes. Para oferta ou conclusão de contrato de consumo, os comerciantes eletrônicos devem disponibilizar, em local de destaque e de fácil visualização, as seguintes informações $\left(\right.$ Art. $\left.2^{\circ}\right)$ :

I - nome empresarial e número de inscrição do fornecedor, quando houver, no Cadastro Nacional de Pessoas Físicas ou no Cadastro Nacional de Pessoas Jurídicas do Ministério da Fazenda;

II - endereço físico e eletrônico, e demais informações necessárias para sua localização e contato;

III - características essenciais do produto ou do serviço, incluídos os riscos à saúde e à segurança dos consumidores;

IV - discriminação, no preço, de quaisquer despesas adicionais ou acessórias, tais como as de entrega ou seguros;

$\mathrm{V}$ - condições integrais da oferta, incluídas modalidades de pagamento, disponibilidade, forma e prazo da execução do serviço ou da entrega ou disponibilização do produto; e

VI - informações claras e ostensivas a respeito de quaisquer restrições à fruição da oferta.

Em verdade, essa lista contem informações já exigidas de qualquer comerciante e não poderia deixar de ser requerida para aqueles inseridos no ambiente da internet. Aliás, nesse espaço cibernético, devemos considerar que outras imposições se colocam tais como o endereço eletrônico. O importante é que as informações estejam no caminho da lisura e da confiança das relações de consumo eletrônicas, resguardando o consumidor de eventuais 
fraude e imputando responsabilidades não somente para o fornecedor direto do produto, como também do próprio provedor de acesso. Evidentemente que tais responsabilidades devem estar de acordo com os deveres a eles imputados e retratar as condutas desestimuladas pela lei.

Exemplificando: caberá ao provedor ter um controle mínimo dos agentes que postam mensagens em seus ambientes. Não das mensagens propriamente ditas, que fique bem claro, mas que tenha mecanismos de reconhecimento dos usuários e de denúncias de fraudes ou abusos cometidos dentro do seu veículo de informação. Assim, o dever do provedor de acesso será ter ferramentas de denúncia e de reconhecimento. Somente com o nãocumprimentodesses deveres é que se poderá imputar responsabilidades para o provedor sobre o conteúdo abusivo ou fraudes ali incorridos.

\section{Responsabilidades pelo fato ou vício do produto nas relações de comércio eletrônico}

Ponto crucial do comércio eletrônico é a questão das responsabilidades. A ausência de regras específicas para a lesão em ambiente virtual somado à complexidade do sistema cibernético, com suas múltiplas variações de mecanismos e de agentes, torna o assunto ainda mais espinhoso. O Decreto Presidencial 7.962/13, as Notas Técnicas do SENACON, assim como as Leis $\mathrm{n}^{\circ} 9.610 / 98, \mathrm{n}^{\circ} 12.737 / 12$ e $\mathrm{n}^{\circ}$ 12.965/14 não regularam a totalidade da matéria, preocupando-se em regular de forma mais genérica as responsabilidades desse campo. A questão que se põe é: seria mesmo necessário e salutar uma regulação mais detalhadas por meio de lei? O assunto, na doutrina e na jurisprudência, por óbvio, gera divergência.

O fato é que, no tema das responsabilidades no ambiente da internet, as regras legais são abertas tanto sob o ponto de vista do Código Civil quanto sob o ponto de vista do Código de Defesa do Consumidor. E essa abrangência trazida na norma traduz-se em um direito que vem se adequando à velocidade das mudanças no trato virtual. Ou seja, por vezes, a regulação específica seria salutar, mas, como regra, a amplitude semântica da norma enseja maior alcance da norma, atualizando o ordenamento pela via interpretativa. Isso exige evidentemente um aplicador do direito comprometido com os valores assegurados pelo Código, sopesando o equilíbrio salutar das relações de consumo, observadas agora no contexto da internet. Em outras palavras, há que se exigir do exegeta considerações sobre direitos e deveres de ambas as partes nessa relação, sem que se inviabilize o comércio 
eletrônico ou se infrinja direito do consumidor; sem que se permita enriquecimentos sem causa de quaisquer das partes ou o estímulo a atitudes contrárias aos ditames maior do direito posto. Assim, por vezes, caberá dar razão ao fornecedor, inviabilizando atitudes oportunistas de consumidores que se utilizam de má-fé.

Mantem-se a responsabilidade objetiva fundada no risco da atividade e a verificação, em cada caso, das expectativas legítimas do consumidor. Segundo o prof. Flávio Tartuce, a responsabilidade objetiva é o "justo equilíbrio, em uma correta harmonia entre as partes, em todos os momentos relacionados com a prestação e o fornecimento". ${ }^{6}$ Possui a característica de ser independe de prova do elemento subjetivo, atribuindo deveres para o fornecedor em função do risco de sua atividade. Permanece o dever do consumidor em provar o dano e o nexo causal entre a conduta do fornecedor e o dano. A lógica é que quem aufere o bônus, deve arcar com o ônus. Veda-se a internalização do bônus e a socialização do ônus, de modo que a atividade comercial, cujo intuito é sempre lucrativo (bônus), não poderá deixar de considerar os riscos (ônus) por ela ensejados.

A responsabilidade, contudo, não será interpretada sozinha. Deverá ser analisada de acordo com a expectativa legítima gerada no consumidor. Assim, é esse elemento, trazido em formato de cláusula geral, é que irá determinar se existe ou não responsabilidade civil no caso de danos. Caberá ao interprete autêntico analisar cada caso em concreto para identificar a expectativa legítima criada. É um conceito, portanto, fundado na tópica, isto é, definível apenas quando diante de uma problemática individualizada. De antemão, a lei não confere sentido delimitado ao termo.

As limitações de responsabilidade no caso de dano devem estar previamente esclarecidas para o consumidor e seu consentimento quanto a essas regras deverá ser dado de forma informada e apartada. Limitações, ainda que apartadas, trazidas com um cronometro para o consumidor, não devem prevalecer.

\section{Responsabilidade dos sites: site-fornecedor e site-comerciante}

O site se equipara a estabelecimento do fornecedor ou do comerciante: aplicam-se as mesmas regras quanto ao vício e ao fato do produto/serviço. Ou seja, quanto ao vício, a responsabilidade é solidária e objetiva perante o consumidor e, quanto ao defeito, a 
responsabilidade continua sendo objetiva apenas aosite-fornecedor esubjetiva do sitecomerciante, imaginando este como aquele que apenas intermedeia produtos alheios. Cabe considerar que o site-fornecedor é o próprio fabricante do produto, detendo o conhecimento do bem; enquanto que o site-comerciante é aquele que transaciona produtos de terceiros, desconhecendo as qualidades técnicas do bem submetido ao seu comércio eletrônico.

Para fins de prevenir suas responsabilidades, caberá ao site-comerciante, de revenda de produtos de terceiros, praticar algumas medidas preventivas de responsabilidade tais como: (i)Estabelecer um sistema de controle na recepção de anúncios e na verificação da idoneidade da informação; (ii) Manter ferramenta de fácil acesso aos usuários para denúncias de ilicitudes acometidas; (iii) Atuar de forma eficaz assim que informado de irregularidades; (iv) Recusar produtos/serviços cujo conteúdo fira, flagrantemente, os princípios de direito do consumidor; (v) Pesquisar sobre a idoneidade do fornecedor e do produto/serviço oferecido; (vi) Utilizar-se de mecanismos com identificação precisa da autoria da informação (número de IP) e dos conteúdos ilícitos veiculados (com a menção das URL's).

Tais medidas traduzem a ideia de responsabilidade subjetiva desses sites-comerciantes que só responderão caso descumpram seus deveres de tutela e de resguarda. Seja mediante controle prévio do próprio fornecedor ou de seu produto, seja mediante controle repressiva com base em denúncias dos próprios usuários, os direitos do consumidor está resguardado ao mesmo tempo em que o autor da infração é perfeitamente identificável. Assim, o sitecomerciante tem mecanismos de defesa ele mesmo contra o fornecedor.

Mas e o contrário, será que acontece? Até que ponto há responsabilidade civil do titular do domínio do comércio eletrônico se este estivesse, com seu procedimento, causando danos ao titular da marca? A tendência da jurisprudência tem sido em conferir maior proteção ao titular da marca, fornecedor, responsabilizando o domínio, site-comerciante, dos abusos acometidos sobre a marca. E esta interpretação tem sido feita com base em analogia da teoria do estabelecimento comercial sobre o domínio e na aplicação dos dispositivos da Lei ${ }^{\circ}$ 9.610/98 quanto a marca.

\section{Tipos de provedores e suas responsabilidades}

Para se falar da responsabilidade dos provedores é preciso, em primeiro, ter noção da existência de seus vários. É possível identificar cinco grandes espécies de provedor hoje no ambiente da internet, cada um com sua função dentro do todo. 
O primeiro deles, e mais elementar, é chamado de Provedor de backboneou Servidor. Nele está a estrutura de rede, lugar do próprio tráfego de informações. É a coluna vertebral, como tradução do termo em inglês, da internet. Não tem relação direta ou indireta com os usuários da internet e, logo, não poderá ser responsabilizados por vícios ou defeitos ocorridos no comércio eletrônico.

O segundo tipo é o Provedor de acesso, onde o serviço oferecido é a conexão à internet de forma exclusiva ou não. Controla apenas o fluxo de mensagem, sem, contudo, ter qualquer poder de controlar o conteúdo trocado. É o caso dos Hostings que concedem o uso e o gozo de um site virtual com a contrapartida de pagamento de um preço, em formato muito semelhante ao da locação. Se põe na relação de forma passiva, apenas viabilizando o fluxo de dados e a troca de informações entre os usuários. Nesse caso, há responsabilidade solidária do provedor de acesso no caso de vício/defeito de produtos/serviços adquiridos pelos consumidores no âmbito da sua web porém com determinadas limitações que veremos mais adiante. Tudo dependerá da abrangência que se dará ao artigo 7, parágrafo único, do CDC.

A terceira espécie é o Provedor de correio eletrônico, que veiculam comunicação e informação entre usuários. Exemplo deles é o Hotmail ou o Gmail. Funciona tal como uma empresa de correio física, recebe as "cartas" e as repassa para seus destinatários, sem qualquer controle de seus conteúdos.

O Provedor de conteúdo comparece como o quarto tipo de provedor, só armazenando informações de terceiros, tal qual uma empresa de estocagem, só que ao invés de guardar bens físicos o faz com conteúdos de textos de outros sujeitos. É o caso do Google ou do Facebook. Aqui, como há acesso público dessas informações armazenadas, existe um verdadeiro potencial lesivo também estocado, ensejando responsabilidades seja para quem insere conteúdo seja para o provedor que o estoca. Segundo relata Parisier: "De um dia para outro, o Facebook deixou de ser uma rede de páginas conectadas e se tornou um jornal personalizado com notícias sobre (e criado por) nossos amigos." E continua: "Zuckerberg e sua equipe encorajavam os usuários: quanto mais dados fornecessem à empresa, melhor seria sua experiência on-line e mais eles voltariam ao site." ${ }^{7}$ O potencial lesivo disso é enorme. Por dessas características, o provedor de conteúdo poderá ser responsabilizado na justa medida da possibilidade em controlar esses conteúdos quando notificado por outros usuários do sistema. Mais adiante voltaremos ao tema com mais detalhes. 
Por fim, estão o Provedor de informação em quinto lugar, como aqueles que criam as informações. São exemplos deles o Mercado livre ou o buscapé. São provedores que organizam e criam um site, cujo ambiente e conteúdo são protegidos por direitos autorais. Assim, diferentemente do Provedor de acesso, cuja relação é passiva com o fornecedor, no caso do Provedor de informação, o vínculo é ativo, de forma a ser mais que uma locação de ambiente virtual mas uma atribuição de espaço dentro do próprio estabelecimento do provedor sendo que este ambiente, ao mesmo tempo que lhe concede espaço para se mostrar aos seus potenciais consumidores, também chancela suas atividades, tal qual um selo de confiabilidade. Essa garantia implícita, trazida pelo próprio ambiente do provedor, qualifica a relação em ativa e cria uma legítima expectativa no destinatário final que será considerada no tema das responsabilidades.

Diante disso, percebe-se de antemão que a diversidade de provedores anda de mãos dadas com as diferentes responsabilidades ali imputadas. Assim, nem sempre a responsabilidade do provedor poderá ser objetiva e solidária, haja vista que se assim se entendesse, a lei inviabilizaria o próprio comércio eletrônico. A questão se resolverá com uma simples indagação: qual a abrangência do art. 7, parágrafo único, do CDC?

Cada intérprete dará a sua resposta a essa importante pergunta. Nesse artigo, opta-se por solucionar o problema da abrangência com base em um dos elementos essenciais da responsabilidade civil: o nexo de causalidade. Assim, já que a regra no CDC quanto a responsabilidade civil é a objetiva, cumpre pensar a matéria com força nos elementos por detrás desse tipo de responsabilidade, de modo que, ainda que não exija a prova do dolo ou da culpa, para ser validamente imputada requer que se prove conduta (ação ou omissão), dano (salvo quando presumido em lei) e nexo causal. Assim, o elemento de ligação assume uma importância enorme com relação a matéria e deve ser compreendido casuisticamente conforme esses diferentes tipos de provedores, sem se incorrer a generalizações causadores de injustiça.

Com relação à responsabilidade dos provedores, a regra de ouro que se deve ter em mente é a seguinte: responsabiliza quando existe algum tipo de fator de vínculo entre o dano e a conduta do provedor. Diante dessa regra maior, é possível pensar em diferentes situações.

Há responsabilidade do provedor quando este participa por qualquer meio diretamente nas atividades do art. $3^{\circ} \mathrm{CDC}$, que define o conceito de fornecedor. Assim, enquadrando-se a 
atividade do provedor em quaisquer das hipóteses desse preceito legal, o provedor assume a qualidade de fornecedor e assim será considerado para efeitos de responsabilidades.

Uma segunda hipótese onde há responsabilidade do provedor será por motivo deste fazer parte da cadeia do ganho/bônus. E, já se sabe: quando há bônus, haverá seu correlato ônus. Desse modo, se o provedor recebe algum tipo de comissão sobre o percentual de vendas realizadas por intermédio de seu site, ou tem participação societária com o fornecedor, ou ainda é parceiro deste ou, de forma geral, há algum interesse negocial do provedor na realização do comércio eletrônico, caberá responsabilidade solidária entre provedor e fornecedor. E assim tem sido afirmado pela jurisprudência dos tribunais estaduais:

o serviço prestado pela ré, de apresentar o produto ao consumidor e intermediar negócio jurídico, recebendo comissão pela concretização do contrato, enquadra-se nas normas do CDC ( $\operatorname{art} .3, \S 2^{\circ}$, Lei n. $8.078 / 90)^{8}$

Inclui-se ainda, como uma terceira causa de responsabilização, o fato do provedor de alguma forma influenciar a operação de compra e venda ou na expectativa legítima do consumidor. É o caso de sites de intermediação que, ainda que não ganhe percentuais sobre o negócio, são renomados e conferem legitimidade à operação. O consumidor jamais fecharia negócio com aquele fornecedor se não fosse pela sua apresentação (e chancela) inserida no site do provedor, que, no caso, é do tipo de acesso. Essa terceira situação é a mais complicada pois admite discricionariedade perigosa na interpretação da lei. Quando se sabe quando um site adquire tal importância que chega ao ponto de chancelar a compra e venda na internet? Sob quais critérios deve-se interpretar a matéria? A lei não responde mas, de fato, a existência de relação de confiança no provedor, atribuída pelo consumidor também ao fornecedor, gera legitima expectativa e deve, portanto, ensejar responsabilidades.

E assim tem sido entendido nos tribunais:

Embora atue a demanda Mercado Livre como mera intermediária de negócios...se verifica a culpa da intermediária por possibilitar a veiculação de selo de vendedor certificado em favor de estelionatário $[\ldots] .^{9}$

Vendedora cadastrada no site da ré no momento da compra, conferindo confiabilidade aos negócios. ${ }^{10}$

O serviço prestado pela recorrente consiste em mera intermediação de compra e venda, pelo que não tem responsabilidade em caso de inexecução do negócio. ${ }^{11}$ 
Por fim, cabe apontar uma última situação de responsabilidade de Provedores. Como já apontado acima, em regra, tais provedores não são responsáveis pelos defeitos ou vícios do produto ou serviço. Podem ser imputados quando se teve a oportunidade de valorar a ilegalidade do conteúdo da informação ou sua danosidade para terceiros e nada fez. Assim, responde por uma omissão ilícita, um descumprimento de seu dever de ação, i.e., de agir para remover ou bloquear o acesso a conteúdo ilícito quando notificado. Assim, nessa hipótese, a responsabilidade é decorrente de ilícito por omissão do provedor, sendo passível de ser imaginada seja pelo provedor de acesso seja pelo provedor de conteúdo. Este posicionamento se alinha perfeitamente ao entendimento atual da jurisprudência, conforme julgados abaixo quanto a provedor de acesso:

Responde a empresa titular do site pelas mercadorias não entregues, mormente quando liberou os valores sem maiores cuidados em relação ao consumidor. ${ }^{12}$

Hospedeiro que deve responder pelo prejuízo suportado pelo consumidor - veículo publicitário que impõe o dever de controlar a idoneidade dos expositores. ${ }^{13}$

Assim como quanto à decisão seguinte quanto ao provedor de conteúdo:

Deve o provedor, ao ser comunicado que determinado texto ou imagem tem conteúdo difamatório, retirá-lo imediatamente, sob pena de responder solidariamente com o autor direto do dano. ${ }^{14}$

4. Com efeito, dada a moldura fática delineada, e diante da precisão do conteúdo do vídeo indicado e da existência de perícia nos autos a sugerir a possibilidade de busca pelo administrador do site, reafirma-se entendimento segundo o qual o provedor de internet - administrador de redes sociais -, ainda em sede de liminar, deve retirar informações difamantes a terceiros manifestadas por seus usuários, independentemente da indicação precisa, pelo ofendido, das páginas em que foram veiculadas as ofensas (URL's). 5. A jurisprudência da Casa é firme em apregoar que a responsabilidade dos provedores de internet, quanto a conteúdo ilícito veiculado em seus sites, envolve também a indicação dos autores da informação (número de IP). ${ }^{15}$

Aliás, esse último contexto de responsabilidade dos provedores de conteúdo tem ganhado importância na mídia e, paralelamente, na jurisprudência. E não poderia deixar de ser diferente haja vista os direitos de intimidade e à vida privada de pessoas e empresas que estão em jogo e os perigos existentes com julgamentos sumários, sem provas, disseminados acriticamente na rede mundial de computadores, geradores de danos substancialmente potencializados e linchamentos públicos de inocentes inclusive. Essas conclusões podem ser observadas em julgado proferido pelo Ministro Luis Felipe Salomão 
1. Atualmente, saber qual o limite da responsabilidade dos provedores de internet ganha extrema relevância, na medida em que, de forma rotineira, noticiam-se violações à intimidade e à vida privada de pessoas e empresas, julgamentos sumários e linchamentos públicos de inocentes, tudo praticado na rede mundial de computadores e com danos substancialmente potencializados em razão da natureza disseminadora do veículo. Os verdadeiros "apedrejamentos virtuais" são tanto mais eficazes quanto o são confortáveis para quem os pratica: o agressor pode recolher-se nos recônditos ambientes de sua vida privada, ao mesmo tempo em que sua culpa é diluída no anonimato da massa de agressores que replicam, frenética e instantaneamente, o mesmo comportamento hostil, primitivo e covarde de seu idealizador, circunstância a revelar que o progresso técnico-científico não traz consigo, necessariamente, uma evolução ética e transformadora das consciências individuais. Certamente, os rituais de justiça sumária e de linchamentos morais praticados por intermédio da internet são as barbáries típicas do nosso tempo. Nessa linha, não parece adequado que o Judiciário adote essa involução humana, ética e social como um módico e inevitável preço a ser pago pela evolução puramente tecnológica, figurando nesse cenário como mero expectador. [...]. ${ }^{16}$

Certamente, o poder judiciário, como intérprete autêntico da lei, deverá empreender um esforço maior na aplicação do direito e seus correlatos deveres no tocante às infrações acometidas no ambiente da internet. Deve repreender essas barbáries típicas do nosso tempo, trazendo consequências graves para o fim de desestimular essas condutas hostis, primitivas e covardes, conforme aludido no julgado, transformando impositiva e paulatinamente as consciências individuais em sentido da atitude ética e responsável.

Nessa linha, crimes como esses, podendo resultar em linchamentos públicos de inocentes, não podem ficar sem resposta jurídica. E, desse modo, é preciso repreender o autor da mensagem. Não sendo possível localizá-lo, caberá responsabilizar o veículo, ou seja, o próprio provedor, ainda que ele não seja autor imediato da mensagem. Necessariamente, aqui, estamos diante de uma responsabilidade subsidiária em seu sentido estrito: requer uma sucessão, uma ordem a ser seguida.

\section{Responsabilidades do site de intermediação: provedor de acesso ou de informação}

Tendo em vista que os debates sobre responsabilidades no comércio eletrônico estão mais centrados nos site de intermediação, cabe aprofundar a análise nesse sentido.

Intermediar significa promover a aproximação entre fornecedores e consumidores. $\mathrm{O}$ intermediador presta serviço de aproximação, sendo regulado pelo Artigo $3^{\circ}$, $\S 2^{\circ}$, do CDC. Tal como todo fornecedor de serviços é remunerado, direta ou indiretamente. Sabemos que 
para se dar a relação de consumo quanto a prestação de serviços, a remuneração é fundamental. Por outro lado, esse conceito de remuneração não pode ser interpretado de forma limitada, mas considerando o mercado e as várias possibilidades em que a efetiva e real remuneração se dá. Assim, na interpretação do artigo $3^{\circ}, \S 2^{\circ}$, do CDC admite-se inserido no conceito de remuneração todos os ganhos que aquela situação propicia seja por intermédio da contraprestação das partes seja com a comercialização de espaços de publicidade do site. A remuneração, portanto, poderá ocorrer pela via de quaisquer agentes incluídos nessa operação ou no site, não exigindo a lei que seja feita diretamente pelo usuário ou comprador.

Como prestador de serviços, para muitos, deve-se aplicar para o site de intermediação as regras do artigo 14 do $\mathrm{CDC}$, observado o dever de segurança em relação ao serviço imputado pela lei. O site de intermediação responderá, portanto, em face do intermediado (seu consumidor) pela reparação de danos causados por defeitos relativos à sua prestação de serviços de intermediação, bem como por informações insuficientes ou inadequadas sobre a fruição e riscos decorrentes da própria relação de intermediação.

Interessante notar que, em havendo prestação de serviços, entre o site de intermediação e o intermediado será feito contrato e imputadas todas as responsabilidades contratuais estabelecidas nesse documento. Além das previstas no instrumento, serão também consideradas as responsabilidades extracontratuais, decorrentes de lei, nos casos de defeito e dano. Com relação à primeira, cabe identificar ser o contrato, como o próprio nome o diz, o documento próprio para se averiguar direitos e deveres imputados. As informações no site não compõe esse documento sob o ponto de vista do consumidor, ainda que o contrário não seja verdadeiro. Dito de outro modo, o fornecedor não se eximirá de seu dever de segurança, ainda que exclua esse dever, parcial ou totalmente, mediante mensagem posta no site. Vejamos entendimento atual da jurisprudência a respeito:

[...]2. O prestador de serviços responde objetivamente pela falha de segurança do serviço de intermediação de negócios e pagamentos oferecido ao consumidor. 3. O descumprimento, pelo consumidor (pessoa física vendedora do produto), de providência não constante do contrato de adesão, mas mencionada no site, no sentido de conferir a autenticidade de mensagem supostamente gerada pelo sistema eletrônico antes do envio do produto ao comprador, não é suficiente para eximir o prestador do serviço de intermediação da responsabilidade pela segurança do serviço por ele implementado, sob pena de transferência ilegal de um ônus próprio da atividade empresarial explorada. $^{17}$ 
Por outro lado, não será razoável exigir do site de intermediação que seja responsabilizado por vícios do produto oferecidos pelo intermediado. Cabe ter em mente que o site de intermediação não vende produtos em si mesmos considerados mas, sim, os serviços de intermediação. Responderá como fornecedor por esses e não pelos vícios ou defeitos do produtos.

Mas, evidentemente, que a imputação de responsabilidades segue os deveres dos agentes, de modo a ser possível imaginar outras situações em que o site de intermediação é trazido para responder determinados fatos. Nesse caso, em face do dever de segurançaé possível exigir dele o dever de possuir informações sobre a identidade de quem atua por seu intermédio. Apenas na falta dessa informação é que o tornará responsável. Ora, isso não é nenhuma novidade, pois segue a regra principal prevista nos incisos I e II do artigo 13 do CDC. O site de intermediação é igualmente responsável pela reparação dos danos causados aos consumidores por defeitos decorrentes do produto quando o fabricante, o construtor, o produtor ou o importador não puderem ser identificados ou o produto ser fornecido sem identificação clara de seu fabricante, produtor, construtor ou importador. E responderá objetivamente, independentemente da existência de culpa. E ao descumprir com seu dever de segurança, o site de intermediação será sancionado pela lei com base na regra da responsabilidade civil.

Aliás, nessa linha, cabe considerar as hipóteses em que, por ausência de ferramenta de controle de a idoneidade da informação, o site de intermediação poderá ser imputado por conteúdos difamatórios ou mesmo ilícitos. Em relação ao provedor de acesso, o que se sanciona, em verdade, não é o conteúdo propriamente dito, que é de autoria de terceiro, mas o próprio fato de inexistir ferramenta em seu endereço eletrônico para que o conteúdo seja denunciado por seus usuários. Isso aconteceu em site de intermediação de serviços de acompanhantes, nos quais foram inseridos os dados de pessoa fora do ramo, levando a abalos psicológicos e outros danos que não poderia ficar sem resposta do direito. É a decisão:

[...]4. No caso em apreço, o site $\mathrm{O}$ click permitiu a veiculação de anúncio em que, objetivamente, comprometia a reputação do autor, sem ter indicado nenhuma ferramenta apta a controlar a idoneidade da informação. Com efeito, é exatamente no fato de o veículo de publicidade não ter se precavido quanto à procedência do nome, telefone e dados da oferta que veiculou, que reside seu agir culposo, uma vez que a publicidade de anúncios desse jaez deveria ser precedida de maior prudência e diligência, sob pena de se chancelar o linchamento moral e público de terceiros. 5. Mostrando-se evidente a responsabilidade civil da empresa Mídia 1 Publicidade Propaganda e Marketing, 
proprietária do site O click, configurada está a responsabilidade civil da TV Juiz de Fora, proprietária do site ipanorama.com, seja por imputação legal decorrente da cadeia de consumo, seja por culpa in eligendo. 6. Indenização por dano moral arbitrada em $\mathrm{R} \$ 30.000,00$ (trinta mil reais). ${ }^{18}$

Melhor determinando o fato-causa da responsabilização do site, não se trata, em verdade, de um agir culposo mas, sim, de uma omissão em seu dever de segurança, na qual, com ou sem culpa, deve ser imputada e sancionada ao intermediador pelo direito.

Por derradeiro, cabe ainda considera a possibilidade de o site de intermediação se colocar como responsável pelo produto/serviço de forma expressa. Nesse caso, assume a posição de garantidor e todas as consequências civis, administrativas e, até, penais desta garantia.

\section{Provedor de conteúdo ou de aplicações: Responsabilidades das redes sociais}

Outro aprofundamento que se faz necessário é no tocante às responsabilidades das redes sociais ou dos usuários delas. Cada qual deverá atuar nos limites de seus direitos e conforme suas obrigações.

Primeiramente, com relação àresponsabilidades das redes sociais, caberá aplicar o entendido já desenvolvido acima de que o conceito de remuneração do artigo $3^{\circ}, \S 2^{\circ}, \mathrm{CDC}$, é amplo, abarcando pagamentos diretos ou indiretos. Assim, mesmo redes sociais que nada cobram de usuários, ao se utilizar de outras ferramentas remuneradas por seus intermediados como banners, cookies, etc, ensejam o ganho material necessário para enquadrar essa atividade como prestação de serviço regulada pelo $\mathrm{CDC}$, como se depreende do posicionamento atual do STJ:

o fato de o serviço prestado pelo provedor de serviço de internet ser gratuito não desvirtua a relação de consumo, pois o termo mediante remuneração, contido no art. $3, \S 2^{\circ}$, do CDC, deve ser interpretado de forma ampla, de modo a incluir o ganho indireto do fornecedor ${ }^{19}$

Ademais, cumpre observar que o Marco Civil da Internet (Lei $\mathrm{n}^{\circ} 12.965 / 14$ ) versa expressamente sobre o tem em seu artigo 18, dispondo: "O provedor de conexão à Internet não será responsabilizado civilmente por danos decorrentes de conteúdo gerado por terceiros."

Esse dispositivo buscou regular o importante tema da responsabilidade dos provedores de conteúdo, na medida em que o poder judiciário vemdecidindo em favor da 
responsabilização dos provedores porconteúdoslesivos a terceiros publicados pelos usuários de rede, seja por ação ou seja por omissão. Por exemplo, o STJ obrigou o Google a indenizar em R \$ 20.000 mil reais homem difamado em blog, assim como manteve condenação também do Google por manter no ar mensagens ilícitas inseridas na rede social do Orkut. Nessa decisão, o ministro do STJ Herman Benjamim entendeu que quem viabiliza tecnicamente a veiculação e estimula a criação de comunidades e páginas de relacionamento na internet e tem benefício econômiconão só faz parte da cadeia de fornecedores num sentido amplo como também é tão responsável pelo controle de eventuais abusos e pela garantia dos direitos dos internautas e de terceiros quanto os próprios internautas que geram e disseminam informações ofensivas.No recurso ao STJ, o Google argumentou não dispor de meios técnicos e humanos para fiscalizar, de forma prévia, o ambiente virtual, e o aludido ministro do STJ entendeu ser devido à empresa o ônus de provar essa inviabilidade prática em cumprir a ordem judicial.

Com efeito, esse argumento trazido pelos provedores de conteúdo de não dispor de meios técnicos e humanos para fiscalizar previamente todo o ambiente virtual é bastante comum e, em decisões mais recentes, esse posicionamento do STJ tem sido alterado casuisticamente. Nessa linha, a Lei $\mathrm{n}^{\mathrm{o}}$ 12.965/14 colaborou para aclarar esse fenômeno e as questões sobre responsabilidades que estão por detrás dele, tal como o fez o artigo $15^{\circ}$ do aludido Texto legal:

Art. 15. Com o intuito de assegurar a liberdade de expressão e evitar a censura, o provedor de aplicações de Internet somente poderá ser responsabilizado civilmente por danos decorrentes de conteúdo gerado por terceiros se, após ordem judicial específica, não tomar as providências para, no âmbito e nos limites técnicos do seu serviço e dentro do prazo assinalado, tornar indisponível o conteúdo apontado como infringente, ressalvadas as disposições legais em contrário.

Parágrafo único. A ordem judicial de que trata o caput deverá conter, sob pena de nulidade, identificação clara e específica do conteúdo apontado como infringente, que permita a localização inequívoca do material.

Em nota técnica interna,${ }^{20}$ o Ministério Público Federal mostrou insatisfação em face a esse enunciado entendendo resultar em risco excessivo "direitos do consumidor, a privacidade da pessoa, a proteção integral da criança e do adolescente e a dignidade da pessoa humana ao abrandar a regulação da responsabilidade dos intermediários tal como proposta no Marco Civil 
Diametralmente oposto está o pensamento daqueles que entendem as regras do Marco Civil como a fixação de um regime de proteção semrazoabilidade, onde liberdade de expressão é interpretada de modo absoluto, recebendo proteção superior àquela garantida aos próprios direitos da personalidade.

Divergências sempre existiram, ainda mais quando a solução será equilibrada a partir de políticas públicas que serão testadas na aplicação da norma aos casos em concreto. Hoje o entendimento tem sido no seguinte sentido: haja vista o dever de segurança dos provedores de conteúdo, estes deverão instituir ferramentas de denuncia para não serem imputados de responsabilidades por conteúdos ilícitos de seus usuários. Havendo tal instrumento, feita e atendida a denuncia, nenhum responsabilidade caberá às redes sociais. A regra, portanto, é quanto à sua irresponsabilidade perante fatos de seus usuários, salvo omissão de mecanismos de controle.

\section{Responsabilidades dos usuários em face doprovedor de conteúdo}

Em face dos usuários, cabe considerar que serão responsabilizados por aquilo que postam. Aliás, a regra quanto a ilicitude será sempre perseguir o autor do fato típico. Quem difama, deve responder por isso em termos civis, administrativos e penais.

Um exemplo interessante para ilustrar a matéria é o grupo do facebook chamado "Onde não ir", criado com o fim de orientar os consumidores ao trazer relatos de experiências de outros sujeitos naqueles lugares. A pontuação dada por esses usuários, evidentemente, traz consequências positivas ou negativas aos donos dos estabelecimentos. Somando-se a isso o fato de que a rede de internet propicia um alcance muito maior a essas mensagens postadas, o resultado é que, se o mecanismo for neutro, será de grande valia para o mercado seja para orientar de forma real os usuários e potenciais consumidores desses estabelecimentos seja para estimular o próprio crescimento desses locais, quando usaram dessas informações para melhorar seu negócio. A moeda de troca é que, inexistindo neutralidade/objetividade ou havendo política interna aleatória, de modo que a decisão de deixar ou não o post fique a critério do sistema e não do usuário, passa-se a ter uma ferramenta que pode ser extremamente prejudicial não só ao mercado como principalmente aos demais fornecedores e à livre concorrência. 
É o caso do grupo "ONDE NÃO IR" do facebook. Criado inicialmente para informar ou sugerir os interessados sobre locais que não deveriam ser visitados, muitos dos comentários ali postados fogem do objetivo proposto pelo grupo e, além de ferir a imagem das empresas, muitas vezes sequer possuem um fundamento fático mínimo para embasar tal reclamação. Isso ocorre quando são inseridas frases como "não volto mais a determinado estabelecimento do ramo alimentício pois o mesmo estava 'lotado' e isto é um desrespeito aos consumidores." Há vício ou defeito no serviço de alimentação em restaurante o fato desse estabelecimento estar 'lotado'?Há verdadeiro desrespeito ao consumidor?

O segundo passo, portanto, será examinar as responsabilidades dos usuários desse tipo de comentário, que, pelo excesso, se torna abusivo. E havendo abusos por parte dos consumidores em seus comentários, eventuais danos que venham a causar à imagem dos fornecedores também pode ser punido pelo Poder Judiciário. Ainda que a todos é garantido o direito a livre manifestação de opinião, esta não é absoluta e deve se limitar a partir de onde começa o direito do outro, no caso, do fornecedor-comentado. O usuário não possui o direito de denegrir a imagem do outro, e, em sendo o caso, poderá o fornecedor utilizar-se de medidas judiciais próprias tanto para sanar o dano - como retirar o comentário indesejado da rede - , como ser reparado pelos danos sofridos, seja de ordem material ou moral.

Ainda com relação aos usuários, este também deverá responder por eventuais mensagens ofensivas. E sua responsabilidade deverá ser mensurada levando em consideração o ambiente das redes sociais em que a mensagem ganhaimensa exposição dada pela rede social, numa espécie de publicidade viral. A cada novo compartilhamento, um número incalculável de pessoas é alcançado, tornando-se praticamente inviável a própria interrupção desse fluxo se não considerada intervenção do gestor da rede.

Dado ao grande potencial lesivo, seria possível, lícitoou factível exigir um filtro préviopara evitar que mensagens ofensivas sejam publicadas? Claro que a resposta a essa indagação deve ser negativa. Primeiro, porque um filtro prévio abalaria o direito de liberdade de expressão. Quem deveria fazer esse filtro? Sob quais critérios isso seria feito? Basta trazer essas perguntas para verificar o campo espinhoso em que esse cenário desenha. Segundo, em razão de o filtro prévio ser factível e economicamente inviável para o provedor de conteúdo. Como ele poderia realizar esse controle sobre as milhares de mensagens ali postadas diariamente? O controle inviabilizaria o propósito do próprio provedor em ser um lugar de armazenagem de conteúdo, onde a liberdade de expressão deve imperar. 
O Superior tribunal de justiça tem se posicionado dessa forma, de acordo com o julgado abaixo:

[...] Trata-se, na origem, de ação indenizatória por danos morais em que o recorrido alega ser alvo de ofensas em página na Internet por meio de rede social mantida por provedor. Assim, a Turma deu provimento ao recurso, afastando a responsabilidade do provedor pelos danos morais suportados pelo recorrido, ao entender que os provedores de conteúdo, como o recorrente - que disponibilizam, na rede, informações criadas ou desenvolvidas pelos provedores, sendo esses que produzem as informações divulgadas na Internet -, não podem ser obrigados a exercer um controle prévio do conteúdo das informações prestadas no site por seus usuários, devem, assim que tiverem conhecimento inequívoco da existência de dados ilegais no site, removê-los imediatamente, sob pena de responder pelos danos respectivos, devendo manter, ainda, um sistema minimamente eficaz de identificação de seus usuários, cuja efetividade será analisada caso a caso. Na espécie, o provedor, uma vez ciente da existência de material de conteúdo ofensivo, adotou todas as providências tendentes à imediata remoção do site. Ademais, a rede social disponibilizada pelo provedor mantém um canal para que as pessoas cuja identidade tiver sido violada solicitem a exclusão da conta falsa, bem como para que seja feita denúncia de abuso na utilização de perfis individuais ou comunidades. A recorrente mantém um meio razoavelmente eficiente de rastreamento dos usuários, medida de segurança que corresponde à diligência média esperada de um provedor de conteúdo. ${ }^{21}$

Como se depreende da decisão, havendo sistema minimamente eficaz de identificação de seus usuários, sistema de denúncia da existência de dados ilegais no site, sendo dado conhecimento inequívoco ao provedor pelos usuários dessas das mensagens e feito todo o procedimento para removê-las imediatamente, descabe imputá-lo de qualquer responsabilidade pelos danos respectivos.

\section{Conclusões}

A internet é uma estrutura complexa, em que em uma só relação vários agentes são participantes, exercendo diferentes funções, todos eles partes de um processo só em que a ausência de qualquer das fases inviabiliza o todo. Diante de todo esse novo contexto fáticosocial e de novas imposições regulatórias, com o marco civil da internet, vê-se que é o momento de repensar o tema da responsabilidade civil diante dessa complexidade de relações cibernéticas e sua potencial lesividade que os abusos acometidos nesse ambiente propiciam.

Pela própria impessoalidade (não-presencial) e massificação do e-commerce, o relacionamento virtual exige um grau muito maior de confiança e de segurança entre 
fornecedores e usuários-consumidores, ensejando diferentes graus de responsabilidades conforme sua efetiva atuação em jogo no campo da internet. Buscou-se identificar as razões e os critérios para se dizer que tal ou qual agente deve ser responsabilizado, identificando os fundamentos legais e principiológicos utilizados.

Diante de tudo exposto, vê se que as regras do CDC continuam se aplicando plenamente ao contexto do comércio eletrônico ou mesmo das redes sociais, devendo-se apenas fazer as adaptações e os limites necessários de acordo com o agente e sua atividade na relação. Por isso mesmo, é fundamental conhecer os tipos de provedores existentes, quais suas atuações e como isso se repercute na responsabilidade civil.

\section{Notas de referência:}

1. MARQUES, Cláudia Lima. O Código Brasileiro de Defesa do Consumidor e o Mercosul. In Revista de Direito do consumidor, vol. 8, p. 40.

2. MARQUES, Cláudia Lima. Confiança no comércio eletrônico e a proteção do consumidor: um estudo dos negócios jurídicos de consumo no comércio eletrônico. São Paulo: Revista dos tribunais, 2004, p. 289.

3. BARRETO, Ricardo de Macedo Menna. Redes sociais na internet e direito: a proteção do consumidor no comércio eletrônico. Curitiba: Juruá, 2012, p. 90

4. Vale ressaltar caso citado por Marcel Leonardi demonstrando como a privacidade é pouco compatível com a navegação na internet: “(...) em 2006, o provedor norte-americado de serviços de Internet America Online publicou vinte milhões de registros, contendo as pesquisas efetuadas, ao longo de um período de três meses, por 657 mil usuários de seu mecanismo de busca. O provedor removeu todos os dados capazes de identifica-los, atribuindo a cada usuário um número aleatório. A intenção da empresa era colaborar com estudos acadêmicos. No entanto, poucos dias depois, sem maiores esforços, dois repórteres do Jornal The New York Times conseguiram identificar uma pessoa, utilizando apenas os termos de busca por ela empregados, e descobriram que o 'usuário 4417749' era a Sra. Thelma Arnold, do estado da georgia, que adorava seus três cães e frequentemente buscava informações a respeito das doenças." (LEONARDI, Marcel. Tutela e privacidade na internet. São Paulo: Saraiva, 2012, p. 77)

5. SADDI, Jairo. Valor online: superendividmento. Portal IPEA, Brasília, 25 jun. 2012, Disponível em: http://www.ipea.gov.br. Acesso em 15 fev. 2016.

6. TARTUCE, Flávio; NEVES, Daniel Amorim Assumpção. Manual de direito do consumidor: direito material e processual. 2. Ed. São Paulo: Método, 2013, p. 36.

7. PARISIER, Eli. O filtro invisível: o que a internet está escondendo de você. Rio de Janeiro: Zahar, 2012, p. 38. 
8. RIO GRANDE DO SUL. Tribunal de Justiça, (9a Câmara Cível). Apelação Cível n. 70016093080. Relator: Desembargador OdoneSanguiné. J. 22 nov. 2006. Disponível em: http://www.tj.rs.gov.br. Acesso em 8-7-2008.

9. RIO GRANDE DO SUL. Tribunal de Justiça, (1a Turma Recursal Cível dos Juizados Especiais Cíveis). Recurso Inominado n. 71000620278. Relator: Juiz Clóvis Moacyr Mattana Ramos. J. 24 mar. 2005. Disponível em: http://www.tj.rs.gov.br. Acesso em 8-7-2008.

10. RIO GRANDE DO SUL. Tribunal de Justiça, (2a Turma Recursal Cível dos Juizados Especiais Cíveis). Apelação Cível n. 71000883421. Relator: Juíza Mylene Maria Michel. J. 22 mar. 2006. Disponível em: http://www.tj.rs.gov.br. Acesso em 8-7-2008.

11. PARANÁ, Tribunal de Justiça, (Turma Recursal única do Juizado Especial Cível). Recurso Inominado n. 2004.1527-3/0. Relator: Juiz Vitor Roberto Silva. J. 24/set/04. Disponível em: www.tj.pr.gov.br. Acesso em: 9-7-2008.

12. RIO GRANDE DO SUL. Tribunal de Justiça, (2a Turma Recursal Cível dos Juizados Especiais Cíveis). Recurso Inominado n.71001132117. Relator: Juiz Eduardo Kraemer. J. 22 nov. 2006. Disponível em: http://www.tj.rs.gov.br. Acesso em 8-7-2008.

13. SÃO PAULO. Tribunal de Justiça ( $3^{\mathrm{a}}$ Turma Cível do Colégio Recursal dos Juizados Especiais Cíveis e Criminais). Recurso Inominado n. 30052. Relator: Juiz Roberto SOlimene. J. 19 dez. $2007 . \quad$ Disponível em: http://cjto.tj.sp.gov.br/juris/getArquivo.do?cd.Acordao=2562947. Acesso em: 9-7-2008.

14. BRASIL, Superior Tribunal de Justiça (3 ${ }^{\text {a }}$ Turma), AgRg no AREsp 305681 / RJ, Relator: Ministro Ricardo Villas BôasCueva, J. 11 set. 2014. Disponível em: http://www.stj.jus.br/SCON/jurisprudencia/doc.jsp?livre=305681\&\&b=ACOR\&p=true\&t=\&1 $=10 \& \mathrm{i}=6$. Acesso em: 24/03/2015.

15. BRASIL, Superior Tribunal de Justiça (4a Turma), Recurso Especial 1306157/SP, Relator: Ministro LUIS FELIPE SALOMÃO, DJ 24/03/14

16. BRASIL, SUperior Tribunal de Justiça, 4 $4^{\text {a }}$ Turma, REsp 1306157 / SP, Relator: Ministro Luís Felipe Salomão, DJ 24/03/14.

17. BRASIL, Superior Tribunal de Justiça, 4ª Turma, REsp 1107024 / DF, Relator: Ministra MARIA ISABEL GALLOTTI, 14/12/11.

18. BRASIL, Superior Tribunal de Justiça, 4ª Turma, REsp 997993 / MG, Relator: Ministro LUIS FELIPE SALOMÃO, DJ 06/08/12

19. BRASIL, Superior Tribunal de Justiça, Resp 1.308.830/RS, $3^{\text {a }}$ Turma, Relator: Min. Nancy Andrighi. Brasília, 08/05/12

20. Ofício n ${ }^{\circ} 16339 / 2012$

21. BRASIL, Superior Tribunal de Justiça, REsp 1.186.616-MG, Relator: Min. Nancy Andrighi, julgado em 23/8/2011. 